\title{
Hubungan Pola Penyebaran dan Ketebalan Zona Bijih Endapan Nikel Laterit dengan Topografi Permukaan Pada PT Aneka Tambang Tbk
}

\author{
Fadli \\ Teknik Pertambangan, Fakultas Teknologi Mineral, Universitas Pembangunan Nasional "Veteran" \\ Yogyakarta, Yogyakarta 55281, Indonesia \\ Correspondence: fadlihariani@gmail.com
}

Received: 12 March 2021; Accepted: 23 April 2021; Published: 20 June 2021

\begin{abstract}
Abstrak: Indonesia merupakan negara yang memiliki sumber daya nikel laterit yang berlimpah, mulai dari Sulawesi hingga ke Papua. Oleh karena itu, peneliti melakukan analisis pola sebaran dan ketebalan endapan nikel leterit untuk mendapatkan pola sebaran zona bijih dari endapan nikel laterit berdasarkan topografi permukaan. Adapun metode yang dilakukan adalah menganalisis sampel pemboran dengan $X$ ray spectometer, menganalisis topografi, morfologi dan membuat profil penampang antar sumbu bor untuk menganalisis pola sebaran zona bijih endapan nikel laterit. Data yang dihasilkan dari penelitian ini adalah bentuk topografi perbukitan dengan morfologi bergelombang, miring hingga melandai, dengan kemiringan lereng 20-160. Penampang endapan secara vertikal mengunakan parameter overburden dengan kadar $\mathrm{Ni}<0.90 \%->4 \%$. Penampang serta pola sebaran endapan nikel laterit terbagi 3 warna yaitu coklat untuk kadar $\mathrm{Ni}<0.90 \%$, kuning untuk kadar $\mathrm{Ni} 0,91 \%-1,50 \%$, dan hijau untuk kadar $\mathrm{Ni}>$ $1,51 \%$. Berdasarkan penampang korelasi pada topografi landai, didapatkan kadar yang tinggi serta tebal dan topografi yang berbukit miring ditemukan kadar yang tinggi tetapi ketebalan yang tipis. Secara keseluruhan kadar nikel laterit berkisar $8-16$ meter.
\end{abstract}

Kata Kunci: Topografi, Nikel Laterit, Kadar, Ketebalan, Pola Penyebaran

\begin{abstract}
Indonesia is a country that has abundant nickel laterite resources, from Sulawesi to Papua. Therefore, the researchers analyzed the distribution pattern and thickness of the nickel leterite deposits to obtain the distribution pattern of the ore zones of the laterite nickel deposits based on the surface topography. The method used is to analyze the drilling sample with an X-ray spectometer, analyze the topography, morphology and create a cross-sectional profile between the drill axes to analyze the distribution pattern of the laterite nickel ore deposit zone. The data generated from this study is a hilly topography with a wavy morphology, slanted, and sloping, with a slope of 20-160. The vertical cross section of the sediment uses overburden parameters with Ni content $<0.90 \%->4 \%$. The cross-section and distribution pattern of laterite nickel deposits are divided into 3 colors, namely brown for Ni content $<0.90 \%$, yellow for Ni content $0.91 \%-1.50 \%$, and green for Ni content $>1.51 \%$. Based on the crosssectional correlation on the sloping topography, it was found that high grades and thick and hilly topography found high grades but thin thicknesses. Overall, laterite nickel content ranges from 8 to 16 meters.
\end{abstract}

Keywords: Topography, Nickel Laterite, Grade, Thickness, Distribution Pattern

\section{PENDAHULUAN}

Indonesia merupakan negara terbesar kedua yang memiliki sumber daya nikel dengan jumlah 13\% dari nikel dunia, yang berada di sisi timur Indonesia, diantaranya wilayah di Sulawesi, Halmahera di Maluku Utara, serta Pulau Gap dan Kepulauan Waigeo (Prasetyo, 2016). Proses pemetaan maupun eksplorasi untuk mengetahui secara detail keberadaan dari 
nikel laterit yang dimiliki dari masing-masing daerah tersebut perlu dilakukan (Sari, 2020; Apriajum et al., 2016). Hasil kegiatan pemetaan serta eksplorasi akan menghasilkan data yang menjadi acuan untuk menentukan pola sebaran dan ketebalan nikel laterit yang ada pada daerah yang diteliti (Syahrul \& Darmawan, 2020).

Penentuan pola penyebaran serta ketebalan nikel laterit sangat penting pada saat perhitungan sumber daya dan cadangan mudah untuk diketahui secara detail (Yurnia et al., 2018). Selain itu, pola penyebaran dan ketebalan akan menjadi dasar yang kuat dalam menentukan modeling cadangan nikel laterit (Bargawa \& Amri, 2016; Bargawa et al., 2020) dan proses perencanaan tambang yang akan dikerjakan (Coronas \& Tabaika, 2019).

Penelitian ini dilakukan pada tambang nikel di Kabupaten Kolaka, Provinsi Sulawesi Tenggara, bertujuan untuk membuat suatu pola penyebaran zona bijih endapan nikel laterit berdasarkan hubungannya dengan topografi permukaan pada daerah konsesi PT. Aneka Tambang Tbk.

\section{METODE PENELITIAN}

Penelitian dimulai dengan melakukan studi pustaka, analisis peta topografi hingga morfologi, pengamatan proses pengeboran, analisis $X$ Ray Spectometer untuk mengetahui kadar unsur, senyawa dan ketebalan zona bijih dan pola penyebaran, analisis topografi, pengamatan penampakan morfologi permukaan daerah penelitian, pembentukan profil penampang antar sumbu bor, analisis pola penyebaran zona bijih endapan nikel laterit dan menggambarkan korelasi kandungan kadar nikel laterit dengan topografi.

\section{Studi Pustaka}

Studi pustaka dilakukan mempelajari literatur atau laporan-laporan penelitian terdahulu untuk mendapatkan gambaran umum daerah penelitian.

\section{Analisis Peta Topografi}

Analisis pengamatan proses pemboran dari data coring lubang bor dilakukan dengan dimasukkan ke dalam peta titik bor dan data tersebut di input dalam komputer. Proses ini memberikan gambaran tentang gejala laterisasi, taksiran besarnya penyebaran dan kedalaman zona laterisasi dan juga mengambarkan secara jelas keadaan tanah dan perbedaan warna dari top soil hingga bedrock.

\section{Pengamatan Coring Sampel Pemboran}

Analisis coring sampel pemboran dilakukan dengan cara membuat line lubang bor dari setiap penampang titik bor untuk melihat kedalaman lubang bor (bottom).

\section{Analisis Sampel}

Analisis yang dilakukan yaitu analisis $X$-Ray Spectometer dan kimia dimana $X$-Ray Spectometer untuk mengukur intensitas flourresensi atau pendaflour sinar $\mathrm{X}$ yang dipancarkan oleh sinar $X$ agar mendapatkan persentase kadar unsur yang ada dalam sempel coring dan analisis kimia dengan mencampurkan wet sample ke dalam larutan kimia untuk mendapatkan presentase kadar nikel $(\mathrm{Ni})$ dan besi $(\mathrm{Fe})$.

Data yang diperoleh pada tahap pemboran dan analisis kadar dikorelasikan antara satu titik bor dengan titik lainnya untuk memperoleh gambaran penyebaran nikel di daerah penelitian dan disajikan dalam bentuk peta penyebaran dan penampang (cross section) untuk menggambarkan bagaimana bentuk endapan nikel laterit di bawah permukaan.

\section{HASIL DAN PEMBAHASAN}

\section{Analisis Peta Topografi Daerah Penelitian}

Daerah penelitian memiliki luas kurang lebih $35.000 \mathrm{~m}^{2}$ dan termasuk dalam topografi perbukitan, dengan kemiringan lereng yang bersifat landai dan tingkat pelapukan yang cukup tinggi. Adapun kenampakan dari morfologi pada daerah penelitian, memiliki kondisi 
permukaan bergelombang, berbukit miring dan landai, dimana permukaan yang bergelombang tersebar pada sisi sebelah selatan yang memanjang dari arah barat laut ke arah selatan dengan dengan kemiringan lereng berkisar antara $2^{\circ}$ hingga $8^{\circ}$. Selain itu, morfologi berbukit tersebar dari arah barat laut ke arah selatan, dengan kemiringan lereng berkisar antara $4^{\circ}$ hingga $16^{\circ}$. Kemudian untuk morfologi landai tersebar pada sisi sebelah timur laut dengan kemiringan lereng berkisar antara $2^{\circ}$ hingga $4^{\circ}$.

\section{Pengamatan Coring Sampel Pemboran}

Berdasarkan kenampakan yang ada di lapangan, maka didapatkan deskripsi core zona laterisasi berdsarkan ciri-ciri dari setiap laterit yang meliputi:

\section{- Zona Overburden (OB)}

Zona overburden ditunjukkan dengan warna coklat kemerahan sampai coklat kehitaman ini terdiri dari tanah hasil pelapukan, pembusukan dedaunan oksida besi dan biasa disebut juga dengan tanah humus. Tanah merah merupakan indikasi yang baik untuk mengetahui adanya batuan ultramafik, walaupun tidak selamanya benar.

\section{- Zona Limonit}

Zona limonit ini merupakan tanah hasil pelapukan berwarna merah kecoklatan, mengandung nikel dan besi. Zona ini berupa fragmen fragmen batuan yang berukuran kecil akibat proses pelapukan dari batuan induknya. Tebal zona ini \pm 10 meter.

\section{- Zona Saprolit}

Zona saprolit merupakan batuan yang sudah sangat lapuk, berwarna kuning kehijauan dengan banyak urat-urat garnierit dan krisopras memiliki kadar nikel yang cukup tinggi > $2 \%$.

\section{- Zona Bedrock}

Zona bedrock (batuan dasar) yaitu batuan beku ultrabasa (peridotit) dan serpentinit yang belum lapuk dengan kandungan Fe $<15 \%$. Pada pemboran inti bukit TLC4 lembar 3 daerah Tambang Tengah dilakukan pemboran hingga lapisan bedrock.

\section{Analisis Sampel}

Hasil yang di dapatkan Pada analisis sampel batuan dapat dilihat pada Tabel 1 berikut.

Tabel 1. Data analisis sampel batuan

\begin{tabular}{ccc}
\hline No & Nama Unsur & Kadar $(\%)$ \\
\hline 1 & Nikel $(\mathrm{Ni})$ & $1.51 \%$ \\
\hline 2 & Besi $(\mathrm{Fe})$ & $8,648 \%$ \\
\hline
\end{tabular}

\section{Pengolahaan data}

Dalam proses pembuatan penampang dan intepretasi pola penyebaran laterit memerlukan data elevasi, titik koordinat, dan hasil analisis kadar pemboran sehingga dalam penggambarannya akan terlihat penampang titik bor secara vertikal. Sedangkan untuk pengolahan data pola penyebaran nikel menggunakan perangkat lunak surfer 8 dan perangkat lunak Auto Cad dengan menghubungkan titik bor yang mengandung kadar nikel laterit yang sama.

\section{- Penentuan Ketebalan Zona Bijih Tiap Titik Bor}

Ketebalan zona bijih ditentukan berdasarkan ketebalan dari zona high grade pada titik sumur bor tersebut. Pembagian zona kadar nikel laterit di daerah penelitian dapat dilihat pada Tabel 2 sebagai berikut. 
Tabel 2. Pembagian zona kadar

\begin{tabular}{ccc}
\hline No & Kadar $(\%)$ & Zona \\
\hline 1 & $0-0,9$ & Waste \\
\hline 2 & $0,91-1,50$ & Low grade \\
\hline 3 & $1.51-4$ & High grade \\
\hline
\end{tabular}

Berdasarkan ketentuan di atas maka pembagian tebal tiap titik bor berdasarkan tebal zona high grade seperti pada Tabel 3 berikut.

Tabel 3. Pembagian tebal tiap titik bor berdasarkan zona

\begin{tabular}{|c|c|c|c|c|c|}
\hline $\begin{array}{l}N \\
0\end{array}$ & $\begin{array}{c}\text { No Titik } \\
\text { Bor }\end{array}$ & $\begin{array}{l}\text { Kedalaman } \\
\text { Pemboran (M) }\end{array}$ & $\begin{array}{c}\text { Tebal } \\
\text { Zona } \\
\text { Waste }(\mathrm{M})\end{array}$ & $\begin{array}{l}\text { Tebal Zona } \\
\text { Low Grade } \\
\text { (M) }\end{array}$ & $\begin{array}{l}\text { Tebal Zona } \\
\text { High Grade } \\
\text { (M) }\end{array}$ \\
\hline 1 & $\begin{array}{c}\text { TB.1440 } \\
\text { A }\end{array}$ & $7 \mathrm{~m}$ & $3 \mathrm{~m}$ & $4 m$ & Tidak ada \\
\hline 2 & $\begin{array}{c}\text { TB.1427 } \\
\text { A }\end{array}$ & $13 \mathrm{~m}$ & Tidak ada & $9 \mathrm{~m}$ & $4 m$ \\
\hline 3 & $\begin{array}{c}\text { TB.1355 } \\
\mathrm{A} \\
\end{array}$ & $12 \mathrm{~m}$ & Tidak ada & $9 \mathrm{~m}$ & $3 \mathrm{~m}$ \\
\hline 4 & $\begin{array}{c}\text { TB.1357 } \\
\text { A }\end{array}$ & $9 \mathrm{~m}$ & $1 \mathrm{~m}$ & $5 \mathrm{~m}$ & $3 \mathrm{~m}$ \\
\hline 5 & $\begin{array}{c}\text { TB.1358 } \\
\mathrm{A} \\
\end{array}$ & $8 \mathrm{~m}$ & $1 \mathrm{~m}$ & $7 \mathrm{~m}$ & Tidak ada \\
\hline 6 & TB1360A & $5 \mathrm{~m}$ & Tidak ada & $5 \mathrm{~m}$ & Tidak ada \\
\hline 7 & $\begin{array}{c}\text { TB.1346 } \\
\text { A }\end{array}$ & $13 \mathrm{~m}$ & Tidak ada & $4 m$ & $10 \mathrm{~m}$ \\
\hline 8 & $\begin{array}{c}\text { TB.1345 } \\
\text { A }\end{array}$ & $14 \mathrm{~m}$ & Tidak ada & $3 \mathrm{~m}$ & $11 \mathrm{~m}$ \\
\hline 9 & $\begin{array}{c}\text { TB.1344 } \\
\text { A } \\
\end{array}$ & $17 \mathrm{~m}$ & Tidak ada & $16 \mathrm{~m}$ & $1 \mathrm{~m}$ \\
\hline 10 & $\begin{array}{c}\text { TB.1343 } \\
\text { A }\end{array}$ & $9 \mathrm{~m}$ & Tidak ada & $5 \mathrm{~m}$ & $4 m$ \\
\hline 11 & $\begin{array}{c}\text { TB.1342 } \\
\text { A }\end{array}$ & $11 \mathrm{~m}$ & $2 m$ & $9 \mathrm{~m}$ & Tidak ada \\
\hline 12 & TB.1341A & $10 \mathrm{~m}$ & Tidak ada & $10 \mathrm{~m}$ & Tidak ada \\
\hline 13 & $\begin{array}{c}\text { TB.1340 } \\
\text { A }\end{array}$ & $6 \mathrm{~m}$ & $2 \mathrm{~m}$ & $4 m$ & Tidak ada \\
\hline 14 & $\begin{array}{c}\text { TB.1282 } \\
\text { A } \\
\end{array}$ & $7 \mathrm{~m}$ & Tidak ada & $5 \mathrm{~m}$ & $2 \mathrm{~m}$ \\
\hline 15 & $\begin{array}{c}\text { TB.1272 } \\
\mathrm{A} \\
\end{array}$ & $11 \mathrm{~m}$ & Tidak ada & $3 \mathrm{~m}$ & $8 \mathrm{~m}$ \\
\hline 16 & TB.1271A & $8 \mathrm{~m}$ & Tidak ada & $1 \mathrm{~m}$ & $7 \mathrm{~m}$ \\
\hline
\end{tabular}

\section{Penampang Endapan Nikel Laterit}

Hasil pengolahan data pada 55 titik bor dengan spasi 25 meter diperoleh penampang endapan nikel laterit secara vertikal dengan parameter overburden memiliki kadar $\mathrm{Ni}<$ $0.90 \%$, low grade kadar Ni 0,91\% - 1,50\% dan high grade memiliki kadar Ni dari $1.51 \%-$ $4 \%$ keatas.

Pada penampang dan pola penyebaran endapan nikel laterit terbagi atas 3 warna yaitu warna coklat untuk kadar $\mathrm{Ni}<0.90 \%$, warna kuning untuk kadar $\mathrm{Ni} 0,91 \%-1,50 \%$, dan warna hijau untuk kadar $\mathrm{Ni}>1,51 \%$. 
Pengolahan data penampang dikelompokkan menurut koordinat $X$ yang masing masing diberi nama $\mathrm{X} 1$, dan koordinat $\mathrm{Y}$.

\section{Penampang Korelasi Titik Bor X4}

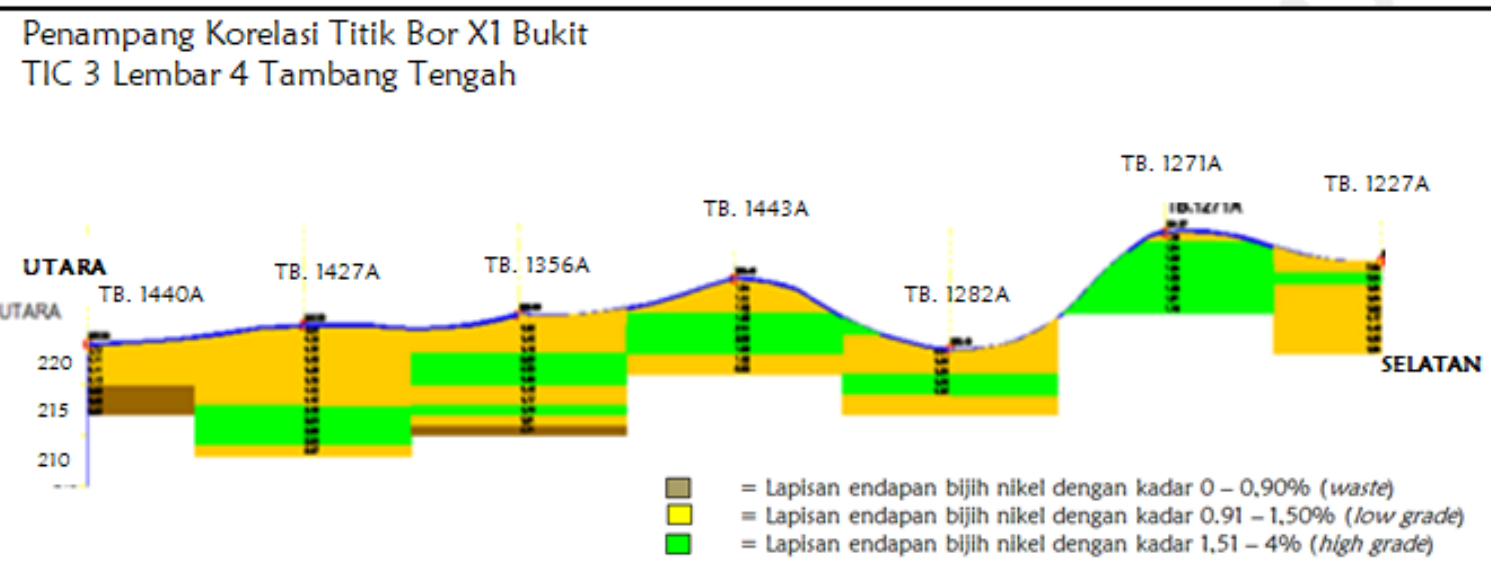

Gambar 1. Penampang korelasi titik bor X1 pada titik bor 1440A, 1427A, 1356A,1343A,1282A, 1271A, 1227A, dari utara ke selatan

Pada penampang $\mathrm{X} 1$ terdapat endapan nikel laterit kadar 0.91\% - 1.50\% (warna kuning) dari arah utara pada TB 1440A ke TB 1427A dengan ketebalan 6 meter. Hal ini disebabkan keadaan topografinya yang curam sehingga tingkat pelapukannya lambat karena air yang diserap hanya sedikit. Pada penampang $X 1$ terdapat juga endapan nikel laterit dengan kadar 1.51\%- 4\% (warna hijau) pada TB 1427A pada meter ke 9 dengan tebal 4 meter. TB 1356A ketebalannya bertambah karena topografinya yang agak landai, maka air yang diserap lebih banyak, sehingga proses pelapukan lebih cepat. Pada titik bor 1343A ke 1282A terdapat juga endapan nikel laterit dengan kadar $0.91 \%-1.50 \%$ (warna kuning) yang heterogen dengan pola endapannya tidak menerus dan menerus (tidak terputus), memiliki ketebalan yang bervariasi. Sedangkan pada TB 1271A ketebalannya bertambah. Hal ini disebabkan topografinya yang landai dan berkurang kembali pada TB 1227A dikarenakan topografinya yang agak curam maka air yang diserap sedikit sehingga proses pelapukan lambat.

\section{Penampang Korelasi Titik Bor Y4}

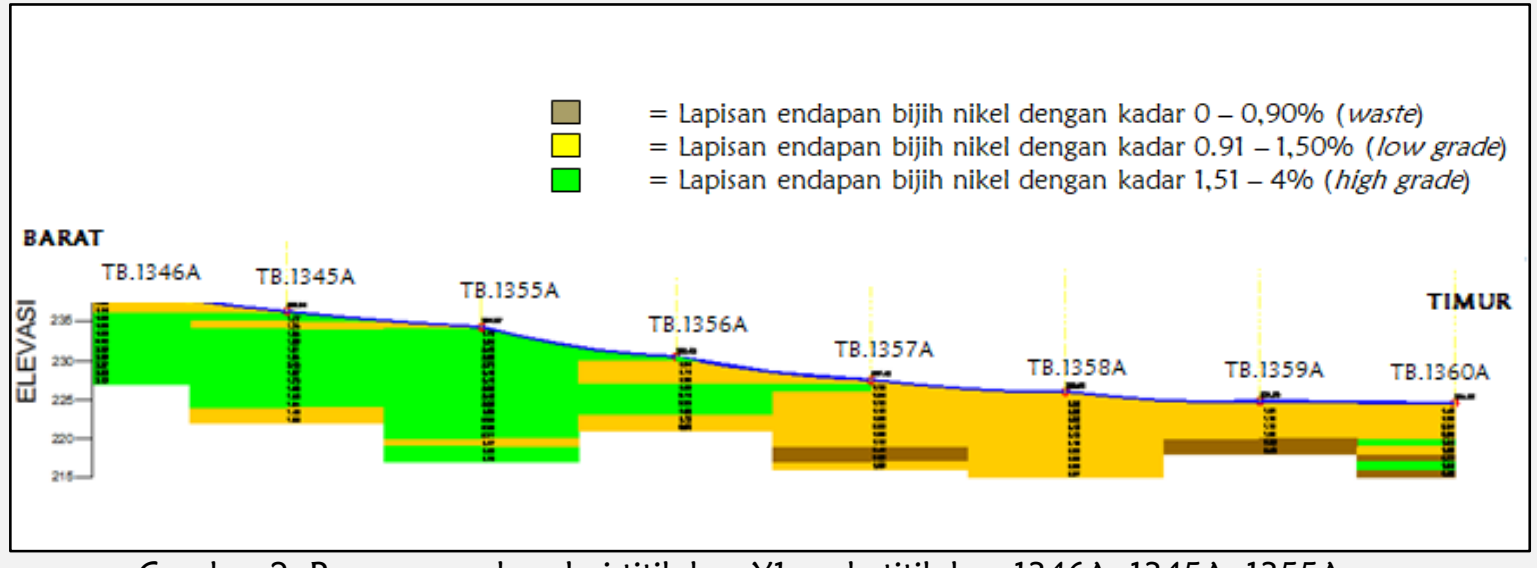

Gambar 2. Penampang korelasi titik bor Y1 pada titik bor 1346A, 1345A, 1355A, 1356A,1357A, 1358A, 1359A, 1360A dari Barat Ke Timur 
Pada penampang $\mathrm{Y} 1$ terdapat endapan nikel laterit dengan kadar 1,51\% - 4\% (warna hijau) pada TB 1346A, TB 1354A, TB 1355 dan TB 1356A yang homogen dengan pola endapannya menerus (tidak terputus), memiliki ketebalan yang bervariasi. Hal ini disebabkan karena topografinya yang landai maka erosi yang terjadi di permukaan lambat, air yang diserap lebih banyak, sehingga proses pelapukan lebih cepat. Pada TB 1357A, 1358A dan $1359 \mathrm{~A}$ dengan kadar $0.90 \%$ - $1.50 \%$ (warna kuning) ketebalannya berkurang. Hal ini disebabkan topografinya yang agak curam maka air yang diserap lebih sedikit sehingga proses pelapukan lambat.

Pada penampang X1 di TB 1360 terdapat juga endapan nikel laterit kadar 0,91\% - 4\% (warna kunig sampai hijau) yang heterogen karena pola penyebaran endapannya yang tidak menerus dan menerus (tidak terputus). Hal ini disebabkan opografinya yang agak curam, air yang diserap lebih sedikit sehingga proses pelapukan lambat.

\section{Hubungan Antara Tebal Zona Bijih (High Grade) dengan Topografi Permukaan}

Berdasarkan penampang korelasi pada Bukit TLC4 lembar 3 Daerah Tambang Tengah

PT Aneka Tambang Tbk, pada topografi yang landai memiliki kadar nikel yang tinggi (high grade) yang memiliki ketebalan yang cukup tebal. Pada topografi berbukit miring mempunyai kadar endapan nikel yang tinggi (high grade) tetapi memiliki ketebalan yang kurang tebal. Kadar endapan bijih nikel laterit $1,51 \%-4 \%$ (high grade). Ketebalan yang dominan tebal terdapat pada bagian Barat TB 1346 (10 meter), TB 1345 (11 meter), TB 1344A (16 meter), TB 1281A (12 meter), TB 1272 (8 meter) dan bagian Timur Menenggara TB 1268A (13 meter), TB 1267 (8 meter), dan Barat Daya TB 1274A (13 meter).

\section{KESIMPULAN}

Endapan nikel laterit yang dijumpai pada bukit TLC4 Lembar 3 daerah Tambang Tengah PT Aneka Tambang Tbk Kecamatan Pomalaa Kabupaten Kolaka Provinsi Sulawesi Tenggara memiliki pola penyebaran yang tidak merata. Hal ini terlihat dari penampang lubang bor secara vertikal dan peta penyebaran rerata kadar endapan nikel laterit. Endapan nikel laterit pada daerah TLC4 Lembar 3 memiliki ketebalan endapan kadar nikel yang berbeda-beda dan pola penyebaran nikel Bukit TLC4 lembar 3 daerah Tambang Tengah tidak merata dan bersifat heterogen, karena pada bagian utara terdapat endapan nikel kadar 0,91\% - 1,50\% warna kuning (low grade), bagian timur dan timur menenggara memiliki ketebalan yang dominan tebal. Endapan nikel laterit kadar 1,51\% - 4\% warna hijau (high grade), dengan pola penyebaran tidak merata dan tidak teratur. Ketebalan yang dominan terdapat pada bagian barat yang cukup tebal.

\section{UCAPAN TERIMAKASIH}

Peneliti mengucapkan apresiasi tertinggi dan ucapan terima kasih kepada PT Aneka Tambang Tbk yang telah memberikan kesempatan kepada peneliti untuk melakukan pengambilan data di perusahaan dan tak lupa para tim eksplorasi di lapangan yang senantiasa membantu dan membimbing penelitian pada saat proses pengambilan data di lapangan. Saya ucapkan terima kasih kepada para pembimbing karena senantiasa memberikan arahan dan pendampingan hingga penelitian dapat diselesaikan, dan yang terakhir yang paling saya hormati dan banggakan yaitu kedua orang tua yang senang tiasa mendukung pendanaan dan menyemangati peneliti.

\section{DAFTAR PUSTAKA}

Apriajum, M. A., Aznah, Y. S., \& Putra, R. O. (2016). Pemetaan potensi nikel laterit berdasarkan analisis spasial studi kasus kecamatan asera kabupaten konawe utara sulawesi tenggara. Seminar nasional kebumian ke 9 peren penelitian ilmu kebumian dalam pemberdayaan masyarakat. 
Bargawa, W. S., Nugroho, S. P., Hariyanto, R., Lusantono, O. W., \& Bramida, R. F. (2020). Geostatistical Modeling of Ore Grade In A Laterite Nickel Deposit. In LPPM UPN "Veteran" Yogyakarta Conference Series Proceeding on Engineering and Science Series (ESS) (Vol. 1, No. 1, pp. 301-310). LPPM UPN “Veteran” Yogyakarta.

Bargawa, W. S., \& Amri, N. A. (2016). Mineral resources estimation based on block modeling. In AIP Conference Proceedings (Vol. 1705, No. 1, p. 020001). AIP Publishing LLC. [CrossRef]

Conoras, W. A., \& Tabaika, M. (2019). Pemodelan dan Estimasi Sumberdaya Nikel Laterit Site Pulau Pakal PT. ANTAM (Persero) Tbk Ubp Nickel Maluku Utara Menggunakan Metode Inverse Distance Weight dan Ordinary Kriging. DINTEK, 12(1), 19-28.

Kusuma, R. A. I., Kamaruddin, H., Rosana, M. F., \& Yuningsih, E. T. (2019). Geokimia Endapan Nikel Laterit di Tambang Utara, Kecamatan Pomalaa, Kabupaten Kolaka, Provinsi Sulawesi Tengara. Jurnal Geologi dan Sumberdaya Mineral, 20(2), 85-92. [CrossRef]

Prasetyo, P. (2016). Sumber Daya Mineral Di Indonesia Khususnya Bijih Nikel Laterit dan Masalah Pengolahannya Sehubungan Dengan Uu Minerba 2009. Prosiding Seminar Nasional Sains dan Teknologi, 2460-8416.

Syahrul, S., Dermawan, A. (2020). "Penyebaran Nikel Laterit Mengunakan Korelasi Lapisan Pada PTVale Indonesia Site Pomalaa, Kabupaten Kolaka, Sulawesi Tenggara”. Jurnal Geomine, 8(1), 40-50. [CrossRef]

Sari, C. F. K. (2020). Pemetaan Endapan Laterit Dalam Menentukan Karakteristik Bijih Nikel Di Pt. Asb - Sulawesi Tengah. Jurnal Vokasi Dewantara, 1(1), 46-54.

Yurnia, F. H., Gusman, M., Octova, A. (2018). Estimasi Cadangan Insitu Melalui Kegiatan Inpit Drill Pada Bukit Everest, Cherokee, Dan Strada Di Pt Antam (Persero) Tbk Ubpn Sultra. Jurnal Bina Tambang. Vol. 3. No. 2, 722-735. under a Creative Commons Attribution-ShareAlike 4.0 International License. 